\title{
A review of daptomycin for injection (Cubicin) in the treatment of complicated skin and skin structure infections
}

\author{
D Matthew Shoemaker \\ Jikerkhoun Simou \\ William E Roland \\ Division of Infectious Diseases, \\ University of Missouri Hospital, \\ Columbia, MO, USA
}

\begin{abstract}
Daptomycin is a novel bactericidal antibiotic with excellent activity against grampositive organisms. It is a large cyclic lipopeptide with a unique mechanism of action. Daptomycin is given once a day and is renally cleared, requiring dose adjustment in patients with impaired renal function. Unfortunately, there have been case reports of resistant grampositive organisms. Daptomycin is generally well tolerated, though myopathy has been reported. 3-hydroxy-3-methylglutaryl coenzyme A (HMG-CoA) reductase inhibitors should be stopped in patients on daptomycin. Daptomycin shows promise in experimental models of endocarditis, meningitis, ventriculitis, and peritonitis, and is currently approved for use in skin and soft-tissue infections. Daptomycin is a welcome newcomer to the gram-positive antimicrobial arsenal.
\end{abstract}

Keywords: daptomycin, lipopeptide, antibiotic, skin infection

\section{Introduction}

With the increasing numbers and types of resistant organisms, there is an increasing need for antibiotics to treat infections caused by them. Daptomycin is a cyclic lipopeptide with a broad spectrum of activity against gram-positive organisms, both aerobic and anaerobic. This includes resistant strains as well such as methicillinresistant Staphylococcus aureus (MRSA), glycopepetide-intermediate Staphylococcus aureus (GISA), vancomycin-resistant enterococci (VRE), coagulase-negative staphylococci (CoNS), and penicillin-resistant Streptococcus pneumoniae (PRSP).

Daptomycin was discovered in the early 1980s, at Eli Lilly and Company (Tally and DeBruin 2000). Daptomycin was initially developed in the late 1980s and early 1990s but was ultimately shelved due to concerns regarding adverse effects, in particular drug-induced myopathy. Cubist Pharmaceuticals Inc. licensed worldwide rights from Eli Lilly and Company in 1997 (Tally and DeBruin 2000).

\section{Basics/mechanism of action}

Daptomycin is derived as a fermentation product from Streptomyces roseospours. The unique structure of daptomycin consists of a 13-member amino acid cyclic lipopeptide with a decanoyl side-chain (Steenbergen et al 2005) (Figure 1). Daptomycin molecular weight is 1620.67 (Cubicin package insert 2003). This is a rather large molecule which may influence its distribution into tissues.

The exact details of daptomycin's mechanism of action are not completely understood. It is believed to have a unique mechanism of action that involves calciumdependent insertion of the lipophilic daptomycin tail into the bacterial cell membrane, 


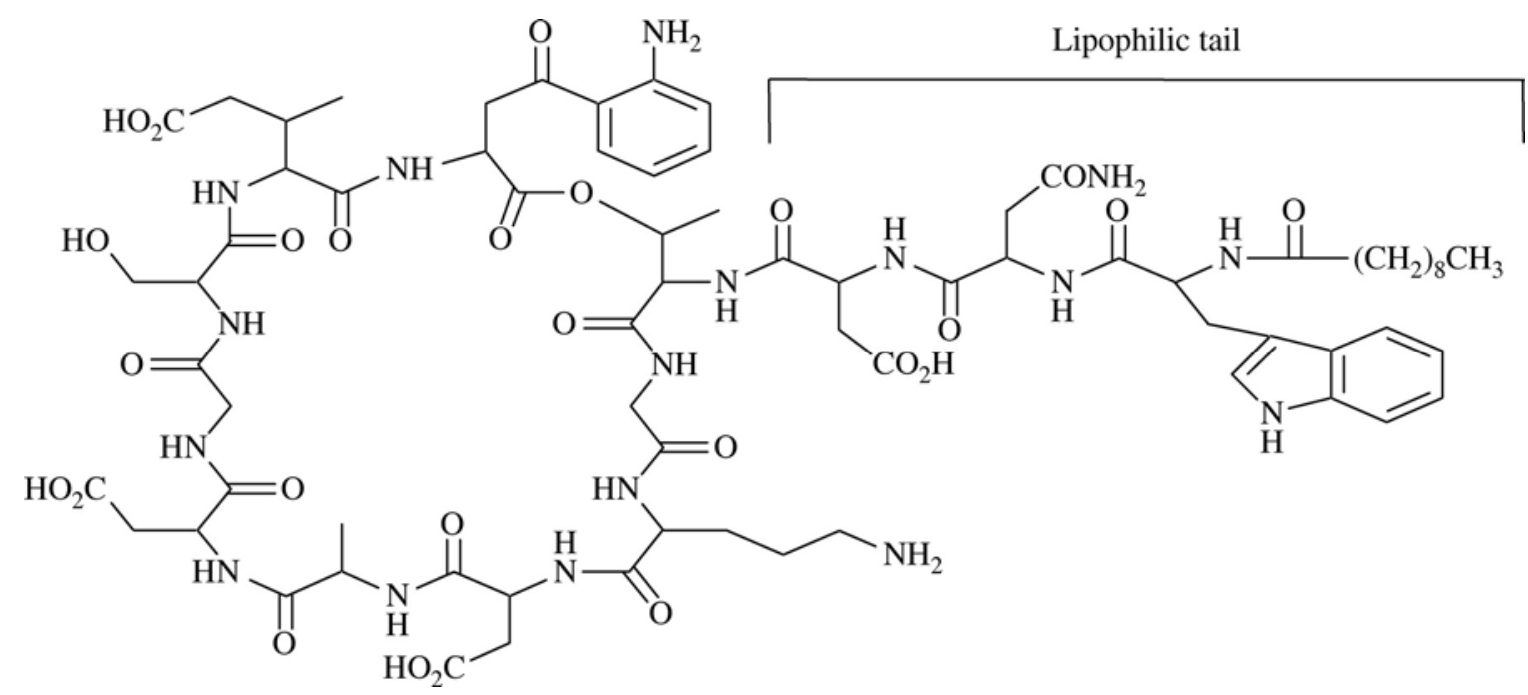

Figure I Structure of daptomycin. Copyright (C) 2005. Reproduced with permission from Steenbergen JN, Alder J, Thorne GM, et al. 2005. Daptomycin: a lipopeptide antibiotic for the treatment of serious Gram-positive infections. J Antimicrob Chemother, 55:283-8.

causing rapid depolarization and potassium ion efflux (Steenbergen et al 2005) (Figure 2). It has been observed that daptomycin causes a calcium-dependent dissipation of the membrane potential $(\Delta \mathrm{psi})$ in Staphylococcus aureus without noticeably affecting the chemical gradient $(\Delta \mathrm{pH})$ across the membrane (Alborn et al 1991). This unique mechanism of action makes daptomycin rapidly bactericidal.

\section{Pharmacokinetics}

Daptomycin exhibits linear pharmacokinetics across a wide range of doses with once daily dosing up to $6 \mathrm{mg} / \mathrm{kg}$ (Figure 3) (Woodworth et al 1992; Dvorchik et al 2003). Daptomycin doses of $8 \mathrm{mg} / \mathrm{kg}$ exhibit a slight nonlinearity (Dvorchik et al 2003).

Approximately $92 \%$ of daptomycin is protein-bound (Woodworth et al 1992). Excretion of the drug occurs primarily via the kidney with approximately $80 \%$ of the total dose, of which two-thirds is intact drug, recovered in the urine (Tally and DeBruin 2000). Due to daptomycin's predominant renal clearance, it requires dose adjustments in those with impaired renal function. Daptomycin clearance in females is estimated to be approximately $80 \%$ that of males with similar renal function, although this has otherwise not been shown to be statistically or clinically significant (Dvorchik et al 2004).

The observed $t_{1 / 2}$ is relatively long ( $\sim 9$ hours) (Dvorchik et al 2003). The long $t_{1 / 2}$ allows for once daily dosing in patients with normal renal function. Daptomycin $t_{1 / 2}$ is increased by 2.3 -fold in patients with creatnine clearance (CLcr) $<40 \mathrm{~mL} / \mathrm{min}$ and 3.5 -fold in patients on dialysis (Dvorchik et al 2004).
Daptomycin remains in the plasma and interstitial fluid and therefore has a small volume of distribution (Dvorchik et al 2003, 2004).

The maximum serum concentration after escalating single daily doses of daptomycin ranged from approximately 55,85 to $95 \mu \mathrm{g} / \mathrm{mL}$, and 115 to $130 \mu \mathrm{g} / \mathrm{mL}$ with doses of 4 , 6 , and $8 \mathrm{mg} / \mathrm{kg}$, respectively (Dvorchik et al 2003). The area under the curve following doses of 4,6 , and $8 \mathrm{mg} / \mathrm{kg} /$ day revealed similar linearity to the $\mathrm{C}_{\max }$ pharmacokinetic data above (Dvorchik et al 2003, 2004).

Daptomycin has been shown to exhibit a post-antibiotic effect (PAE) on Staphylococcus aureus and Streptococcus pneumoniae (Pankuck et al 2003; Safdar et al 2004). The PAE combined with the long $t_{1 / 2}$ of daptomycin allows for once daily dosing in patients with normal renal function.

Daptomycin should not be used to treat pneumonia. This is due to the fact that daptomycin is inhibited by surfactant (Silverman et al 2005).

\section{Spectrum of activity}

As mentioned before, daptomycin has a broad spectrum of activity against gram-positive organisms, both aerobic and anaerobic. This includes resistant strains as well such as MRSA, GISA, VRE, CoNS, and PRSP. Calcium concentration of the media is an important factor in interpreting susceptibility testing (Fuchs et al 2000). The manufacturer recommends susceptibility testing with broth microdilution using Mueller-Hinton broth adjusted to a calcium content of $50 \mathrm{mg} / \mathrm{L}$ (Cubicin package insert 2003). Below are the minimum inhibitory concentration of antiinfective needed to inhibit the growth of $90 \%$ of strains 


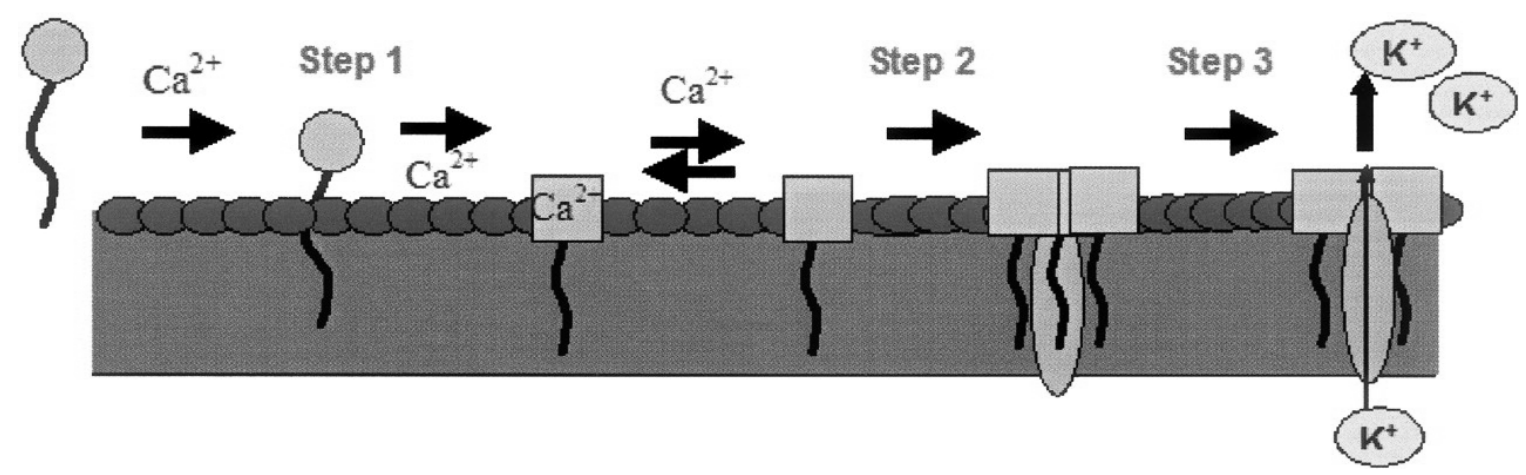

Figure 2 Proposed mechanism of action of daptomycin. Hypothetical steps: step I, daptomycin binds to the cytoplasmic membrane in a calcium-dependent manner; step 2, daptomycin oligomerizes, disrupting the membrane; step 3, the release of intracellular ions and rapid cell death. Copyright $@$ 0 2005. Reproduced with permission from Steenbergen JN, Alder J, Thorne GM, et al. 2005. Daptomycin: a lipopeptide antibiotic for the treatment of serious Gram-positive infections. J Antimicrob Chemother, 55:283-8.

$\left(\mathrm{MIC}_{90} \mathrm{~s}\right)$ of a variety of gram-positive organisms from various in vitro studies:

- Staphylococcus aureus * MIC 0.5 mg/L (Streit et al 2004) (*without a breakdown into MSSA and MRSA).

- MSSA MIC 0.25 to $0.5 \mathrm{mg} / \mathrm{L}$ (Wise et al 2001; Fuchs et al 2002; Richter et al 2003).

- MRSA MIC 0.5 to $1.0 \mathrm{mg} / \mathrm{L}$ (Wise et al 2001; Fuchs et al 2002; Richter et al 2003).

- GISA MIC 0.125-0.5 mg/L (Akins and Rybak 2000, 2001). No differences were seen for susceptibility of vanA, vanB1, and vanD strains (Jevitt et al 2003).

- VRSA: Daptomycin was found to be bactericidal against a VRSA (strain HMC3) isolated in Pennsylvania, US that was resistant to vancomycin through the presence of the vanA resistance gene; it also contained mecA, $\operatorname{erm}(\mathrm{A}), \operatorname{erm}(\mathrm{B}), \operatorname{tet}(\mathrm{K})$ and $\operatorname{aac}\left(6^{\prime}\right)-\operatorname{aph}\left(2^{\prime \prime}\right)$, conferring resistance to licensed $\beta$-lactams, macrolides, tetracycline and aminoglycosides (Bozdogan et al 2003).

- CoNS 0.5 mg/L (Wise et al 2001; Fuchs et al 2002; Sader et al 2004; Streit et al 2004).

- Enterococcus fecalis** MIC 1 to $2 \mathrm{mg} / \mathrm{L}$ (Wise et al 2001; Richter et al 2003; Streit et al 2004) (**Enterococci were defined as vancomycin susceptible and those not further defined. If known to be VRE then stated as such).

- Vancomycin-resistant Enterococcus fecalis MIC 1 to $4 \mathrm{mg} / \mathrm{L}$ (Richter et al 2003; Sader et al 2004).

- Enterococcus faecium MIC 2 to $4 \mathrm{mg} / \mathrm{L}$ (Wise et al 2001; Richter et al 2003; Streit et al 2004).

- Vancomycin-resistant Enterococcus faecium MIC 2 to $4 \mathrm{mg} / \mathrm{L}$ (Richter et al 2003; Sader et al 2004).

- Streptococcus pneumoniae MIC $0.25 \mathrm{mg} / \mathrm{L}$ (Wise et al 2001; Streit et al 2004).

- $\quad$ PRSP MIC 0.25 mg/L (Sader et al 2004).
Susceptibility breakpoints for as set forth by the Food and Drug Administration (FDA), which are the same as those from the National Committee for Clinical Laboratory Standards, are as follows (Cubicin package insert 2003; Streit et al 2005):

- Staphylococcus aureus (MSSA and MRSA) $<1 \mathrm{mg} / \mathrm{L}$

- Streptococcus spp. (S. pyogenes, S. agalactiae, and $S$. dysgalactiae subsp. equisimilis) $\leq 1 \mathrm{mg} / \mathrm{L}$

- Enterococcus fecalis (vancomycin-susceptible only) $<4 \mathrm{mg} / \mathrm{L}$

\section{Resistance}

There appears to be a low rate of spontaneous resistance to daptomycin with limited increases in MIC and relative ease of treatment of resistant isolates (Silverman et al 2001).

Population analysis of three Staphylococcus aureus isolates for which the daptomycin MICs were $8 \mathrm{mg} / \mathrm{mL}$ showed a pattern of homogeneous resistance (Jevitt et al 2003).

There have been multiple case reports of gram-positive organisms with daptomycin resistance, these include MRSA (Mangili et al 2005), Enterococcus faecium (Sabol et al 2005; Long et al 2005), and Enterococcus fecalis (MunozPrice et al 2005).

\section{Adverse drug reactions}

Early in clinical trials daptomycin was found to have skeletal muscle effects that included myopathy with muscle weakness and elevated serum creatine phosphokinase (CPK). Further testing using a dog model revealed that this was more of a problem with fractioned dosing that could be overcome by changing the dosing schedule to once daily from every twelve hours (Oleson et al 2000). 
DAPTOMYCIN DISPOSITION

321

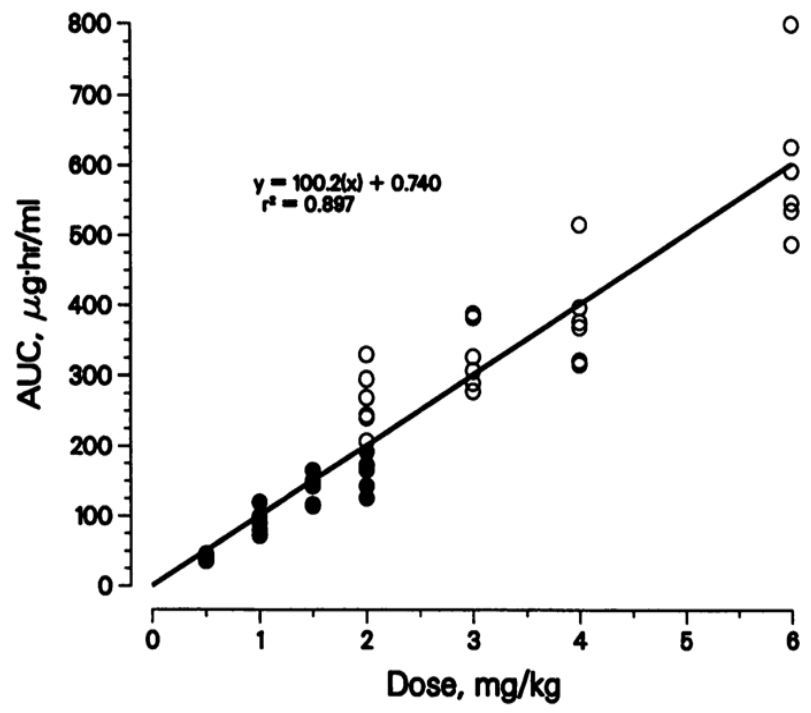

FIG. 3. Linearity of dose versus AUC between 0.5 and $6 \mathrm{mg} / \mathrm{kg}$. -, AUCs from study B; O, AUCs from study C.

Figure 3 Linearity of dose versus area under the curve (AUC). Copyright $(\odot)$ 1992. Reproduced with permission from Woodworth JR, Nyhart EH, Brier GL, et al. 1992. Single-dose pharmacokinetics and antibacterial activity of daptomycin, a new lipopeptide antibiotic, in healthy volunteers. Antimicrob Agents Chemother, 36:318-25.

Daptomycin is generally well tolerated (Dvorchik et al 2003; Arbeit et al 2004). A large randomized trial evaluating the safety and efficacy of daptomycin for the treatment of complicated skin and skin-structure infections (cSSSI) involving 1092 patients revealed the frequency, distribution, and severity of adverse events to be similar for daptomycin and standard therapy (Arbeit et al 2004) (Table 1).

There was a case report of significant myopathy with daptomycin without pronounced CPK elevation (CPK $<500 \mathrm{U} / \mathrm{L}$ ) at a dose of $6 \mathrm{mg} / \mathrm{kg}$ intravenously per day (Veligandla et al 2004). There has also been a case report of myopathy and possible hepatotoxicity in a patient with underlying chronic liver disease, but the elevations in the transaminases were mild (aspartase aminotransferase 239 U/ $\mathrm{L}$ and alanine aminotransferase $48 \mathrm{U} / \mathrm{L}$ ) (Echevarria et al 2005). It is recommended by the manufacturer that in patients with unexplained signs and symptoms of myopathy in conjunction with $\mathrm{CPK}$ elevation $>1000 \mathrm{U} / \mathrm{L}$, or in patients without reported symptoms who have marked elevation in CPK ( $\geq 10 \mathrm{x}$ ULN), daptomycin should be discontinued (Cubicin package insert 2003).

\section{Drug-drug interactions}

Daptomycin is without any known significant drug-drug interactions. Nonetheless, the manufacturer recommends giving consideration to temporarily discontinuing use of HMG CoA reductase inhibitors while patients receive daptomycin (Cubicin package insert 2003). This is recommended due to the potential confusion that may arise if a patient on an HMG CoA reductase inhibitor were to experience myopathy or an increase in CPK level.

\section{Clinical uses}

Daptomycin is currently only approved for the treatment of cSSSI caused by susceptible Staphylococcus aureus (MSSA and MRSA), Streptococcus spp. (S. pyogenes, S. agalactiae, and $S$. dysgalactiae subsp. equisimilis), and Enterococcus fecalis (vancomycin-susceptible only) (Cubicin package insert 2003; Arbeit et al 2004). This includes diabetic foot ulcers (Arbeit et al 2004; Lipsky and Stoutenburgh 2005).

Daptomycin has proven to be effect in multiple experimental endocarditis models. In a retrospective analysis of 49 patients with endocarditis due to gram-positive organisms, daptomycin dosed at $>6 \mathrm{mg} / \mathrm{kg}$ intravenously every 24 hours showed high cure rates (Levine and Lamp 2005).

There have also been case reports of successful treatment of prosthetic valve endocarditis in humans (Mohan et al 2005). Daptomycin trials in human endocarditis are currently in progress.

In an experimental animal (rabbit) model of meningitis due to penicillin- and quinolone-resistant Streptococcus pneumoniae, daptomycin looked promising when compared with the combination of ceftriaxone and vancomycin (Cottagnoud et al 2004).

In an experimental model of Staphylococcus aureus ventriculitis in hydrocephalic rabbits, daptomycin was detectable in the periventricular white matter but in amounts too small to quantitate. Daptomycin killed more Staphylococcus aureus more rapidly than vancomycin in this model (Haworth et al 1990).

Daptomycin also appears to be a promising for the treatment of peritoneal dialysis-associated peritonitis due to staphylococci and streptococci in an in vitro peritoneal dialysate model (Hermsen et al 2003).

A trend toward equivalent efficacy between intravenous daptomycin and intravenous ciprofloxacin was observed in the treatment of gram-positive urinary tract infections in which Enterococcus faecalis and Staphylococcus aureus were the most common gram-positive pathogens (Naber et al 2004). Based on the previously mentioned susceptibilities and the fact that daptomycin is predominately renally excreted, one would predict that daptomycin should be 
Table I Adverse events that occurred in $>2 \%$ of patients in either treatment group (Arbeit et al 2004)

\begin{tabular}{lll}
\hline & \multicolumn{2}{c}{$\mathbf{n}(\%)$ of patients } \\
\cline { 2 - 3 } & $\begin{array}{l}\text { Daptomycin } \\
\text { group } \\
\text { (n=534) }\end{array}$ & $\begin{array}{l}\text { Comparator } \\
\text { group }^{\mathbf{a}}\end{array}$ \\
(n=558)
\end{tabular}

Note: ${ }^{a}$ Cloxacillin, flucloxacillin, nafcillin, oxacillin, or vancomycin.

Abbreviations: CPK, creatine phosphokinase.

Copyright $\odot$ 2004. Reproduced with permission from Arbeit RD, Maki D, Tally FP, et al 2004. The safety and efficacy of daptomycin for the treatment of complicated skin and skin-structure infections. Clin Infect Dis, 38:1673-81.

effective in the treatment of urinary tract infections due to such pathogens, but this warrants further studies.

Daptomycin was at least equivalent to vancomycin against chronic foreign body infections due to Staphylococcus aureus, though vancomycin has poor activity in these infections. In a prospective study of daptomycin in the treatment of prosthetic joint infections, 5 of 7 patients with MRSA infections experienced treatment failures, so the efficacy of daptomycin in the treatment of prosthetic joint infections is uncertain (Rao and David 2005).

Daptomycin should not be used to treat pneumonia. This is due to the fact that daptomycin is inhibited by surfactant (Silverman et al 2005).

\section{Dose}

The dose of daptomycin is $4 \mathrm{mg} / \mathrm{kg}$ intravenously every 24 hours for patients with normal renal function (Cubicin package insert 2003; Arbeit et al 2004). For patients with a creatinine clearance of less than $30 \mathrm{mg} / \mathrm{min}$, including those patients on hemodialysis, continuous ambulatory peritoneal dialysis, or continuous renal replacement therapy (CRRT) which includes continuous arteriovenous hemofiltration $(\mathrm{CAVH})$, continuous venovenous hemofiltration $(\mathrm{CVVH})$, continuous arteriovenous hemodialysis (CAVHD), continuous venovenous hemodialysis (CVVHD), and continuous venovenous hemodialfiltration (CVVHDF), the dose is $4 \mathrm{mg} / \mathrm{kg}$ intravenously every 48 hours (Cubicin package insert 2003; Arbeit et al 2004; Trotman et al 2005). Patients with moderate hepatic impairment receiving daptomycin do not require an adjustment in daptomycin dose or dose regimen (Dvorchik 2004). No adjustment in daptomycin dose or dose regimen should be required based solely on obesity (Dvorchik and Damphousse 2005). An international, multicenter, randomized open label trial using the off-label dose of daptomycin at $6 \mathrm{mg} / \mathrm{kg}$ every 24 hours showed that this dose was similar in efficacy to standard therapy for Staphylococcus aureus bacteremia and endocarditis (Fowler et al 2005).

\section{Conclusion}

Daptomycin is a cyclic lipopeptide antibiotic with excellent activity against gram-positive organisms. Although there have been case reports of daptomycin-resistant grampositive organisms, it has a unique mechanism of action that renders it bactericidal. Daptomycin is given once a day and is renally cleared, requiring dose adjustment in patients with impaired renal function. Daptomycin is generally well tolerated, though myopathy has been reported. Daptomycin is currently approved for use in skin and soft-tissue infections and shows promise in experimental models of endocarditis, meningitis, ventriculitis, and peritonitis.

\section{References}

Akins RL, Rybak MJ. 2000. In vitro activities of daptomycin, arbekacin, vancomycin, and gentamicin alone and/or in combination against glycopeptide intermediate-resistant Staphylococcus aureus in an infection model. Antimicrob Agents Chemother, 44:1925-9.

Akins RL, Rybak MJ. 2001.Bactericidal activities of two daptomycin regimens against clinical strains of glycopeptide intermediateresistant Staphylococcus aureus, vancomycin-resistant Enterococcus faecium, and methicillin-resistant Staphylococcus aureus isolates in an in vitro pharmacodynamic model with simulated endocardial vegetations. Antimicrob Agents Chemother, 45:454-9.

Alborn WE, Allen NE, Preston DA. 1991. Daptomycin disrupts membrane potential in growing Staphylococcus aureus. Antimicrob Agents Chemother, 35:2282-7. 
Arbeit RD, Maki D, Tally FP, et al 2004. The safety and efficacy of daptomycin for the treatment of complicated skin and skin-structure infections. Clin Infect Dis, 38:1673-81.

Bozdogan B, Esel D, Whitener C, et al. 2003. Antibacterial susceptibility of a vancomycin-resistant Staphylococcus aureus strain isolated at the Hershey Medical Center. J Antimicrob Chemother, 52:864-8.

Cottagnoud P, Pfister M, Acosta F, et al. 2004. Daptomycin is highly efficacious against penicillin-resistant and penicillin- and quinoloneresistant pneumococci in experimental meningitis. Antimicrob Agents Chemother, 48:3928-33.

Cubicin package insert. 2003. Lexington, MA: Cubist Pharmaceuticals Inc.

Dvorchik BH, Brazier D, DeBruin MF, et al. 2003. Daptomycin pharmacokinetics and safety following administration of escalating doses once daily to healthy subjects. Antimicrob Agents Chemother, $47: 1318-23$

Dvorchik B, Arbeit RD, Chung J, et al 2004. Population pharmacokinetics of daptomycin. Antimicrob Agents Chemother, 48:2799-2807.

Dvorchik B 2004. Moderate liver impairment has no influence on daptomycin pharmacokinetics. J Clin Pharmacol, 44:715-22.

Dvorchik DH, Damphousse D. 2005. The pharmacokinetics of daptomycin in moderately obese, morbidly obese, and matched nonobese subjects. $J$ Clin Pharmacol, 45:48-56.

Echevarria K, Datta P, Cadena J, et al. 2005. Severe myopathy and possible hepatotoxicity related to daptomycin. J Antimicrob Chemother. 55:599-600.

Fowler V, Cosgrove S, Abrutyn H, et al. 2005. Daptomycin vs. standard therapy for Staphylococcus aureus bacteremia and infective endocarditis [abstract]. 45th Annual International Conference of Antimicrobial Agents and Chemotherapy, 16-19 December, Washington, DC. USA. K-426a-2005

Fuchs PC, Barry AL, Brown SD. 2000. Daptomycin susceptibility tests: interpretive criteria, quality control, and effect of calcium on in vitro tests. Diagn Microbiol Infect Dis, 38:51-8.

Fuchs PC, Barry AL, Brown SD. 2002. In vitro bactericidal activity of daptomycin against staphylococci. J Antimicrob Chemother, 49:467-70.

Haworth CS, Sobieski MW, Scheld WM, et al. 1990. Staphylococcus aureus ventriculitis treated with single-dose intraventricular vancomycin or daptomycin (LY146032): bacterial and antibiotic kinetics in hydrocephalic rabbits. Antimicrob Agents Chemother, 34:245-51.

Hermsen ED, Hovde LB, Hotchkiss JR, et al. 2003. Increased killing of staphylococci and streptococci by daptomycin compared with cefazolin and vancomycin in an in vitro peritoneal dialysate model. Antimicrob Agents Chemother, 47:3764-7.

Jevitt LA, Smith AJ, Williams PP, et al. 2003. In vitro activities of daptomycin, linezolid, and quinupristin-dalfopristin against a challenge panel of staphylococci and enterococci, including vancomycin-intermediate Staphylococcus aureus and vancomycin-resistant Enterococcus faecium. Microbial Drug Resistance, 9:389-93.

Levine DP, Lamp KC. 2005. Endocarditis treated with daptomycin; Experience from a registry [abstract]. 43rd IDSA abstracts, Infectious Diseases Society of America, 6-9 October, 2005, San Francisco, CA, USA. $359, \mathrm{p} 99$.

Lipsky BA, Stoutenburgh U. 2005. Daptomycin for treating infected diabetic foot ulcers: evidence from a randomized, controlled trial comparing daptomycin with vancomycin or semi-synthetic penicillins for complicated skin and skin-structure infections. J Antimicrob Chemother, 55:240-5.

Long JK, Choueiri TK, Hall GS. et al. 2005. Daptomycin-resistant Enterococcus faecium in a patient with acute myeloid leukemia. Mayo Clinic Proceedings, 80:1215-16.
Mangili A, Bica I, Snydman DR et al 2005. Daptomycin-resistant, methicillin-resistant $i$ bacteremia. Clin Infect Dis, 40:1058-0.

Mohan SS, McDermott BP, and Cunha BA 2005. Methicillin-resistant Staphylococcus aureus prosthetic aortic valve endocarditis with paravalvular abscess treated with daptomycin. Heart Lung, 34:6971.

Munoz-Price LS, Lolans K, Quinn JP. 2005. Emergence of resistance to daptomycin during treatment of vancomycin-resistant Enterococcus faecalis infection. Clin Infect Dis, 41:565-6.

Naber KG, Eisenstein BI, Tally FP. 2004. Daptomycin versus ciprofloxacin in the treatment of complicated urinary tract infection due to grampositive bacteria. Infect Dis Clin Pract, 12:322-7.

Oleson FB, Berman CL, Kirkpatrick JB, et al. 2000. Once-daily dosing in dogs optimizes daptomycin safety. Antimicrob Agents Chemother, 44:2948-53.

Pankuch GA, Jacobs MR, Appelbaum PC. 2003. Postantibiotic effects of daptomycin against 14 staphylococcal and pneumococcal clinical isolates. Antimicrob Agents Chemother, 47:3012-14.

Rao N, David R. 2005. A prospective study evaluating the efficacy of for the treatment of prosthetic joint infections [abstract]. 43rd IDSA abstracts, Infectious Diseases Society of America, 6-9 October, San Francisco, CA, USA. 388, p 105.

Richter SS, Kealey DE, Murray CT, et al. 2003. The in vitro activity of daptomycin against Staphylococcus aureus and Enterococcus species. $J$ Antimicrob Chemother, 52:123-7.

Sabol K, Patterson JE, Lewis JS, et al. 2005. Emergence of daptomycin resistance in Enterococcus faecium during daptomycin therapy. Antimicrob Agents Chemother, 49:1664-5.

Sader HS, Streit JM, Fritsche TR, et al. 2004. Antimicrobial activity of daptomycin against multidrug-resistant gram-positive strains collected worldwide. Diagn Microbiol Infect Dis, 50:201-4.

Safdar N, Andes D, Craig WA. 2004. In vivo pharmacodynamic activity of daptomycin. Antimicrob Agents Chemother, 48:36-8.

Silverman JA, Oliver N, Andrew T, et al. 2001. Resistance studies with daptomycin. Antimicrob Agents Chemother, 45:1799-1802.

Silverman JA, Mortin LI, Vanpraagh ADG, et al. 2005. Inhibition of daptomycin by pulmonary surfactant: in vitro modeling and clinical impact. J Infect Dis, 191:2149-52.

Steenbergen JN, Alder J, Thorne GM, et al. 2005. Daptomycin: a lipopeptide antibiotic for the treatment of serious Gram-positive infections. J Antimicrob Chemother, 55:283-8.

Streit JM, Jones RN, Sader HS. 2004. Daptomycin activity and spectrum: a worldwide sample of 6737 clinical Gram-positive organisms. $J$ Antimicrob Chemother, 53:669-74.

Streit JM, Steenbergen JN, Thorne GM, et al. 2005. Daptomycin tested against 915 bloodstream isolates of viridans group streptococci (eight species) and Streptococcus bovis. J Antimicrob Chemother, 55:574-8.

Tally FP, DeBruin MF. 2000. Development of daptomycin for Grampositive infections. $J$ Antimicrob Chemother, 46:523-6.

Trotman RL, Williamson JC, Shoemaker DM, et al. 2005. Antibiotic dosing in critically ill adult patients receiving continuous renal replacement therapy. Clin Infect Dis, 41:1159-66.

Veligandla SR, Louie KR, Malesker MA, et al. 2004. Muscle pain associated with daptomycin. Ann Pharmacother, 38:1860-2.

Wise R, Andrews JM, Ashby JP. 2001. Activity of daptomycin against Gram-positive pathogens: a comparison with other agents and the determination of a tentative breakpoint. J Antimicrob Chemother, 48:563-7.

Woodworth JR, Nyhart EH, Brier GL, et al. 1992. Single-dose pharmacokinetics and antibacterial activity of daptomycin, a new lipopeptide antibiotic, in healthy volunteers. Antimicrob Agents Chemother, 36:318-25. 